See Article page XXX.

\section{Commentary: Maze procedure or no maze procedure: That is the question}

\author{
Kenji Minakata, MD, PhD
}

It has been more than a quarter century since Dr Cox first reported successful treatment of atrial fibrillation (AF) and restoration of sinus rhythm (SR) using a surgical procedure called the "maze procedure." Since then, many investigators have tested different lesion sets and surgical techniques on a range of presentations to identify the risk factors for failure and to assess the effect on quality of life and survival. There have been very few changes/ modifications to the original lesion set of the maze procedure, which has been reported to yield the best outcomes. ${ }^{1,2}$ In this issue of The Journal of Thoracic and Cardiovascular Surgery, Park and colleagues ${ }^{3}$ reported the surgical outcomes of their maze procedure using cryoablation in patients with severe tricuspid regurgitation (TR) and persistent AF. The etiology of TR in their cohort was secondary to the left-sided valvular diseases in most patients. Obviously, the patients in the maze group were less likely to have undergone previous cardiac surgery, had less atrial remodeling, had longer aortic cross-clamp time, and were more likely to undergo tricuspid valve repair than replacement. After propensity score-matching, the authors reported that the maze group had a higher SR restoration rate (54\% at 9 years) and higher freedom from major cardiovascular events, and a similar permanent pacemaker (PPM) implantation rate compared with those of the non-maze group. The authors concluded that the maze

\footnotetext{
From the Division of Cardiovascular Surgery, Cooper Medical School of Rowan University, Camden, NJ.

Disclosures: The author reported no conflicts of interest.

The Journal policy requires editors and reviewers to disclose conflicts of interest and to decline handling or reviewing manuscripts for which they may have a conflict of interest. The editors and reviewers of this article have no conflicts of interest.

Received for publication Nov 7, 2021; revisions received Nov 7, 2021; accepted for publication Nov 8, 2021.

Address for reprints: Kenji Minakata, MD, PhD, Division of Cardiovascular Surgery, Cooper Medical School of Rowan University, One Cooper Plaza, Camden, NJ

08103 (E-mail: minakata-kenji@cooperhealth.edu).

J Thorac Cardiovasc Surg 2021; $\mathbf{\square}: 1-2$

$0022-5223 / \$ 36.00$

Copyright (c) 2021 by The American Association for Thoracic Surgery

https://doi.org/10.1016/j.jtcvs.2021.11.017
}

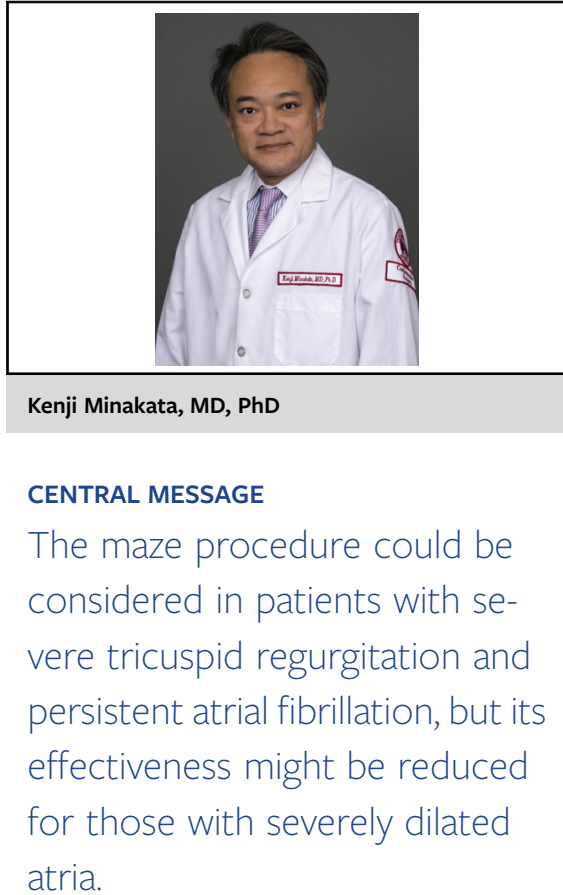

procedure in patients with severe $\mathrm{TR}$ and persistent $\mathrm{AF}$ had an acceptable SR restoration rate with reduced rate of major cardiovascular events. I would like to congratulate the authors on their continuous efforts to refine their technique, which is reflected in their excellent long-term outcomes. That said, I would like to raise a few important points. First, there have been some modifications to the lesion set and the method for dealing with dilated atria during the study period of 23 years. In particular, epicardial coronary sinus ablation was added in their recent series of the patients, which could have improved the outcomes of these patients. Second, assessment of SR restoration was determined only on the basis of "snapshot" electrocardiograms, not on continuous monitoring such as Holter electrocardiogram or loop recording. This often contributes to overestimation of success and might explain why their SR restoration rate fluctuated over time in analyses of patients receiving and not receiving medications. Third, because all of the patients had severe TR in this study, many patients had a dilated right atrium in addition to left atrial dilation. We often encounter this in patients with a very long history of AF associated with severe biatrial dilatation who tend to develop sick sinus syndrome, which more often requires PPM when we add the maze 
procedure. We might be able to decrease the PPM rate in such patients by not applying the maze procedure who are willing to accept permanent AF, but it could be argued that PPM implantation has a negative effect on late outcomes. In fact, the requirement of PPM itself does not mean surgical failure, as long as AF is eliminated with surgical ablation.

\section{References}

1. Cox JL, Churyla A, Malaisrie SC, Kruse J, Pham DT, Kislitsina ON, et al. When is a maze procedure a maze procedure? Can J Cardiol. 2018;34:1482-91.

2. Cox JL, Malaisrie SC, Kislitsina ON, McCarthy PM. The electrophysiologic basis for lesions of the contemporary maze operation. J Thorac Cardiovasc Surg. 2019; 157:584-90.

3. Park I, Jeong DS, Park SJ, Ahn JH, Kim J. Impact of maze procedure in patients with severe tricuspid regurgitation and persistent atrial fibrillation. J Thorac Cardiovasc Surg. 2021. XXX:XXX. 